\title{
Efficacy of short novel antimicrobial and anti-inflammatory peptides in a mouse model of methicillin-resistant Staphylococcus aureus (MRSA) skin infection
}

\author{
This article was published in the following Dove Press journal: \\ Drug Design, Development and Therapy \\ 17 October 2014 \\ Number of times this article has been viewed
}

\section{Mohamed F Mohamed Mohamed N Seleem \\ Department of Comparative Pathobiology, College of Veterinary Medicine, Purdue University, West Lafayette, IN, USA}

Correspondence: Mohamed N Seleem Department of Comparative Pathobiology, College of Veterinary Medicine, Purdue University, 625 Harrison Street, Lynn I298, West Lafayette, IN 47907-2027, USA

Tel + I 7654940763

Fax +I 7654962627

Email mseleem@purdue.edu

\begin{abstract}
The therapeutic efficacy of two novel short antimicrobial and anti-inflammatory peptides (RR and RRIKA) was evaluated in a mouse model of staphylococcal skin infection. RR ( $2 \%$ ) and RRIKA ( $2 \%$ ) significantly reduced the bacterial counts and the levels of proinflammatory cytokines, tumor necrosis factor (TNF)- $\alpha$, and interleukin (IL)-6, in methicillin-resistant Staphylococcus aureus USA 300-0114 skin lesions. Furthermore, the combined therapy of RRIKA (1\%) and lysostaphin (0.5\%) had significantly higher antistaphylococcal and antiinflammatory activity compared to monotherapy. This study supports the potential use of these peptides for topical treatment of methicillin-resistant Staphylococcus aureus skin infections.
\end{abstract}

Keywords: antimicrobial peptides, MRSA, lysostaphin, skin infection, mice

\section{Introduction}

Bacterial infections, especially those caused by Staphylococcus aureus, are the most significant complication encountered in the management of wounds. ${ }^{1}$ Furthermore, multidrug-resistant $S$. aureus strains and their secreted toxins are responsible for interfering with the wound-healing process and creating portals of entry for systemic complications in affected patients. ${ }^{2}$ With the increasing incidence of staphylococcal resistance to topical antimicrobials, such as mupirocin and fusidic acid, ${ }^{3-5}$ there is a pressing need to develop novel antimicrobials and new approaches to circumvent this burgeoning problem. Recently, there has been increased interest in the development of antimicrobial peptides (AMPs) as novel therapeutics, due to their high potency, broad spectrum of activity, and reduced potential for resistance development. ${ }^{6,7}$ In addition to the potent bactericidal activity of AMPs, the recognized anti-inflammatory response of certain AMPs should be an advantage in the treatment of $S$. aureus skin infections. $^{8}$

In a recent study, we described two novel short peptides - RR (WLRRIKAWLRR) and RRIKA (WLRRIKAWLRRIKA) - with potent bactericidal activity in vitro against multiple clinical isolates of methicillin-resistant $S$. aureus (MRSA). ${ }^{6}$ In particular, the peptides were active against the highly virulent MRSA USA 300-0114, a communityassociated strain responsible for outbreaks of staphylococcal skin and soft-tissue infections in the US. ${ }^{9}$ Moreover, RR and RRIKA were superior in reducing adherent biofilms of both $S$. aureus and Staphylococcus epidermidis when compared to conventional antibiotics. Furthermore, both RR and RRIKA enhanced the antistaphylococcal 
activity of lysostaphin in vitro more than 1,000 -fold. ${ }^{6}$ Although lysostaphin demonstrated potent efficacy against MRSA infections in different animal models, ${ }^{10-12}$ its therapeutic potential was hampered by the emergence of bacterial resistance. ${ }^{10,13}$ In light of our previous results, showing enhancement of the antimicrobial effectiveness of lysostaphin against MRSA when combined with AMPs in vitro, ${ }^{6}$ we moved forward with an in vivo experiment in a mouse model of MRSA skin infection.

\section{Materials and methods}

\section{Bacterial isolate}

We obtained the community-acquired MSRA strain NRS384 (MRSA USA 300-0114) isolated from a wound from a patient in Mississippi, USA. The strain is resistant to erythromycin and tetracycline; positive for mec (subtype IV); $p v l^{+/-}$; multilocus sequence type $8^{-}$; eGenomic spa type 1, eGenomic spa repeats YHGFMBQBLO; Ridom spa type t008; agr grp I.

\section{Peptides and antibacterial agents}

RR and RRIKA were synthesized by GenScript (Piscataway, NJ, USA). Recombinant lysostaphin was purchased from Ambi Products (Lawrence, NY, USA). Linezolid and fusidic acid were purchased from Chem-Impex International (Wood Dale, IL, USA).

\section{Mouse infection}

Female BALB/c mice (6-8 weeks old) were obtained from Harlan Laboratories (Indianapolis, IN, USA). All procedures were approved by the Purdue University Animal Care and Use Committee (1207000676). The murine model of MRSA skin infection has been described before. ${ }^{14,15}$ Eight groups of mice $(n=5)$ were inoculated with $40 \mu \mathrm{L}$ of MRSA USA 300 $\left(3 \times 10^{7} \mathrm{CFU}\right)$ intradermally. Forty-eight hours after infection and formation of an open wound, six 6 groups were treated topically with either $2 \%$ fusidic acid, 2\% RR, 2\% RRIKA, $1 \%$ RRIKA, $0.5 \%$ lysostaphin, or $1 \%$ RRIKA plus $0.5 \%$ lysostaphin formulated in $20 \mathrm{mg}$ petroleum jelly. One group received vehicle only (petroleum jelly), and the last group was treated orally with linezolid ( $25 \mathrm{mg} / \mathrm{kg})$. All groups were treated twice a day for 3 days. Twenty-four hours after the last treatment, mice were humanely killed, the area around the wound lightly swabbed with $70 \%$ ethanol, and the wound (around $1 \mathrm{~cm}^{2}$ ) excised for bacterial counting after homogenization in $1 \mathrm{~mL}$ tryptic soy broth.

\section{Cytokine detection}

Enzyme-linked immunosorbent assay (ELISA) development kits for detection of cytokines were purchased from
R\&D Systems (Minneapolis, MN, USA). Homogenized skin lesions after bacterial counting were centrifuged at $15,000 \mathrm{rpm}$ for 10 minutes. The supernatants were removed and kept at $-20^{\circ} \mathrm{C}$ until analyzed. The supernatants were examined for cytokine production: tumor-necrosis factor (TNF)- $\alpha$, interleukin (IL)-6, and IL-1 $\beta$ using ELISA as described before. ${ }^{16}$ Cytokine levels were expressed as percentage change relative to negative control.

\section{Statistical analyses}

Data are presented as means \pm standard deviation. Statistical analyses were performed using GraphPad Prism 6.0 (GraphPad Software, La Jolla, CA, USA). $P$-values were calculated by the two-tailed Student's $t$-test. $P$-values $<0.05$ were considered significant.

\section{Results and discussion}

As shown in Figure 1, all treatments significantly reduced the mean bacterial counts compared with the control group $(P \leq 0.01)$. Among groups treated with monotherapy, the group treated with $2 \%$ RRIKA had the highest reduction in CFU $\left(2.08 \pm 0.20 \log _{10}\right)$, followed by $2 \%$ fusidic acid $\left(1.94 \pm 0.36 \log _{10}\right), 2 \%$ RR (1.83 $\left.\pm 0.30 \log _{10}\right)$, and linezolid $\left(1.74 \pm 0.53 \log _{10}\right)$. Groups treated with $0.5 \%$ lysostaphin or $1 \%$ RRIKA achieved a significant reduction of $1.79 \pm 0.56$ $\log _{10}$ and $1.08 \pm 0.36 \log _{10}$, respectively, when compared with

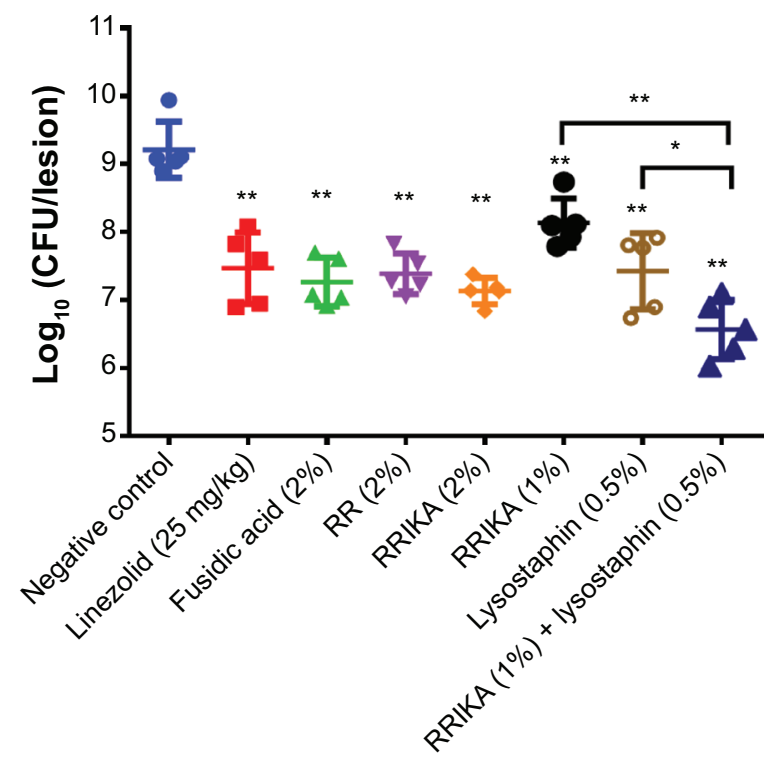

Figure I Efficacy of treatment of methicillin-resistant Staphylococcus aureus skin lesions with RRIKA (2\%), RR (2\%), fusidic acid ( $2 \%)$, linezolid (25 mg/kg), RRIKA (1\%), lysostaphin (0.5\%), combined therapy of RRIKA (I\%) and lysostaphin (0.5\%), and petroleum jelly (negative control) twice daily for 3 days. The two-tailed Student's $t$-test was used to determine statistical significance (a $P$-value $<0.05$ was considered significant).

Notes: $* P<0.05 ; * * P \leq 0.01$. 
the control group $(P \leq 0.01)$ (Figure 1). The combination therapy $(0.5 \%$ lysostaphin with $1 \%$ RRIKA) was significantly more effective than treatment with RRIKA or lysostaphin alone, and achieved statistically significant bacterial reduction of $2.65 \pm 0.44 \log _{10}$ compared to the negative control $(P \leq 0.01)$. The bacterial reduction in the combined therapy was also statistically significant compared to monotherapy
$(P<0.05)$ or control antibiotics $(P<0.05)$. Previously, RR and RRIKA showed potent immunomodulatory activities in vitro through inhibition of mitogen-activated protein kinase (MK2). ${ }^{17,18}$ In this study, topical treatment with RRIKA and RR significantly reduced TNF $\alpha$ and IL- 6 production in MRSA skin lesions. As shown in Figure 2A and B, 2\% RR and 2\% RRIKA reduced the TNF $\alpha$ level by $49 \%$ and

A

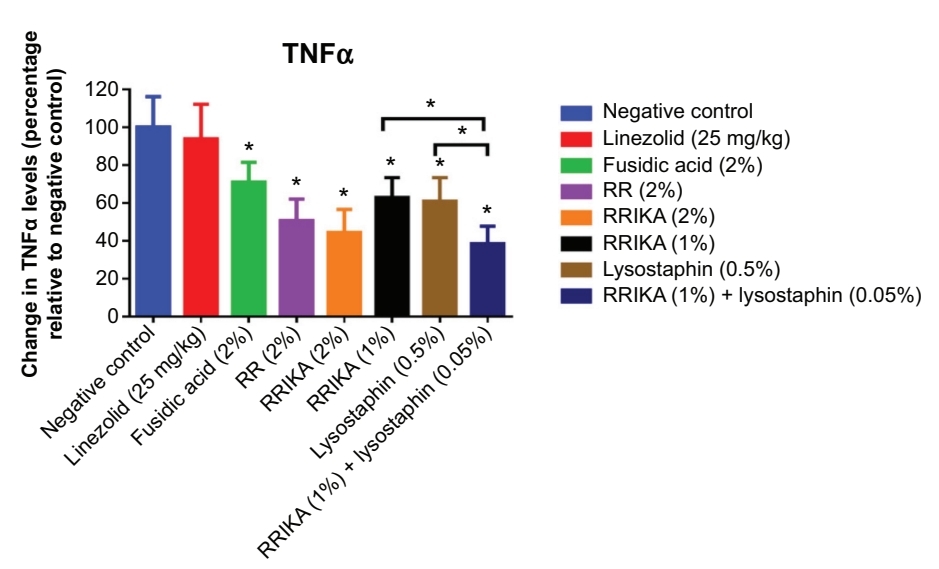

B

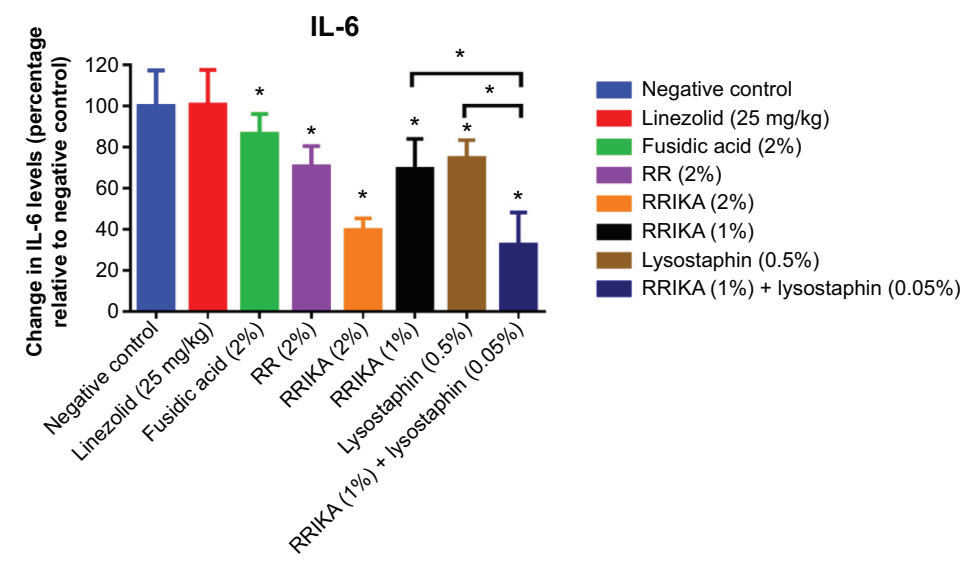

C

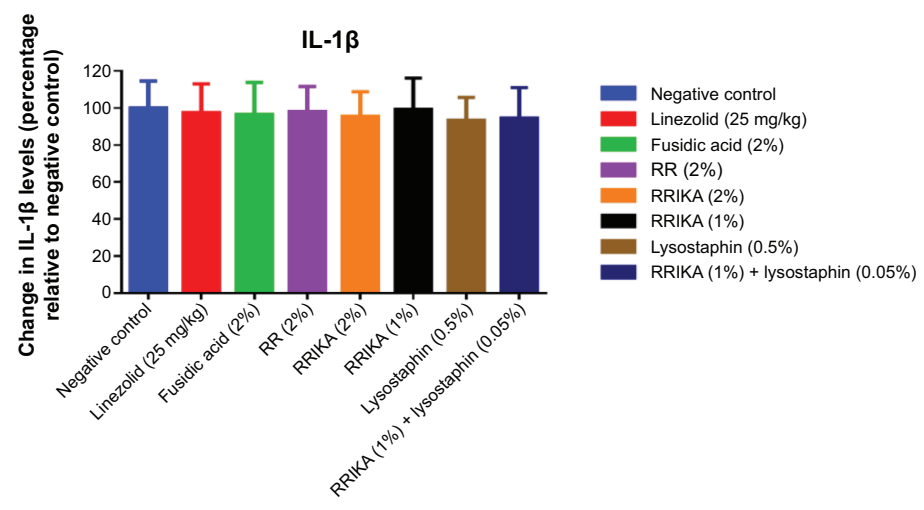

Figure 2 The effect of peptides on cytokines TNF $\alpha(\mathbf{A})$, IL-6 (B), and IL-I $\beta$ (C) production in methicillin-resistant Staphylococcus aureus skin lesions. Tissue homogenate supernatants were examined for cytokine production using the enzyme-linked immunosorbent assay. Cytokine levels were expressed as percentage change relative to negative control. Data are presented as means \pm standard deviation from duplicates consisting of four mice per group. Statistical analysis was calculated by the two-tailed Student's $t$-test. $P$-values $<0.05$ were considered significant $(*)$.

Abbreviations: TNF, tumor necrosis factor; IL, interleukin. 
$56 \%$, respectively, while the IL-6 level was reduced by $29 \%$ and $60 \%$, respectively. Treatment with $0.5 \%$ lysostaphin and $2 \%$ fusidic acid caused $39 \%$ and $29 \%$ reduction of the TNF $\alpha$ level, respectively, and $13 \%$ and $25 \%$ reduction of the IL-6 level, respectively, which is in agreement with previous findings. ${ }^{19,20}$ There was a synergistic anti-inflammatory response observed when $0.5 \%$ lysostaphin was combined with $1 \%$ RRIKA. The combined therapy significantly reduced TNF $\alpha$ and IL- 6 levels by $62 \%$ and $67 \%$, respectively. On the other hand, none of the treatments interfered with IL- $1 \beta$ production, which is necessary for $S$. aureus clearance in cutaneous infections (Figure 2C). ${ }^{21-22}$

In this study, topical application of RR and RRIKA was shown to be very effective in reducing the bacterial load in MRSA skin lesions. Moreover, peptides reduced the release of TNF $\alpha$ and IL-6, which might benefit the healing of infected wounds. ${ }^{23-27}$ In addition, the combination of RRIKA with lysostaphin was significantly more effective in the treatment of MRSA skin lesions than treatment with either peptide alone. This combination therapy is also expected to overcome some of the limitations associated with lysostaphin monotherapy through hindering the emergence of bacterial resistance and lowering the required therapeutic dose.

In conclusion, our findings in MRSA skin lesions should significantly impact and inform efforts to use a combination of anti-inflammatory and AMP therapies as novel topical treatment options for multidrug-resistant pathogens.

\section{Acknowledgments}

Mohamed F Mohamed is supported by a scholarship from the Egyptian Cultural and Educational Bureau (ECEB) in Washington, DC, USA. The bacterial strain used in this study was provided by the Network on Antimicrobial Resistance in Staphylococcus aureus (NARSA) for distribution by BEI Resources, NIAID, NIH: Staphylococcus aureus, strain USA300-0114, NR-46070.

\section{Disclosure}

The authors report no conflicts of interest in this work.

\section{References}

1. Sen CK, Gordillo GM, Roy S, et al. Human skin wounds: a major and snowballing threat to public health and the economy. Wound Repair Regen. 2009;17(6):763-771.

2. Guo S, Dipietro LA. Factors affecting wound healing. $J$ Dent Res. 2010;89(3):219-229.

3. Dobie D, Gray J. Fusidic acid resistance in Staphylococcus aureus. Arch Dis Child. 2004;89(1):74-77.
4. Kresken M, Hafner D, Schmitz FJ, Wichelhaus TA. Prevalence of mupirocin resistance in clinical isolates of Staphylococcus aureus and Staphylococcus epidermidis: results of the Antimicrobial Resistance Surveillance Study of the Paul-Ehrlich-Society for Chemotherapy, 2001. Int J Antimicrob Agents. 2004;23(6):577-581.

5. Chambers HF, Deleo FR. Waves of resistance: Staphylococcus aureus in the antibiotic era. Nat Rev Microbiol. 2009;7(9):629-641.

6. Mohamed MF, Hamed MI, Panitch A, Seleem MN. Targeting methicillinresistant Staphylococcus aureus with short salt-resistant synthetic peptides. Antimicrob Agents Chemother. 2014;58(7):4113-4122.

7. Hancock RE, Sahl HG. Antimicrobial and host-defense peptides as new anti-infective therapeutic strategies. Nat Biotechnol. 2006;24(12):1551-1557.

8. Montgomery CP, Daniels MD, Zhao F, Spellberg B, Chong AS, Daum RS. Local inflammation exacerbates the severity of Staphylococcus aureus skin infection. PloS One. 2013;8(7):e69508.

9. King MD, Humphrey BJ, Wang YF, Kourbatova EV, Ray SM, Blumberg HM. Emergence of community-acquired methicillin-resistant Staphylococcus aureus USA 300 clone as the predominant cause of skin and soft-tissue infections. Ann Intern Med. 2006;144(5):309-317.

10. Kumar JK. Lysostaphin: an antistaphylococcal agent. Appl Microbiol Biotechnol. 2008;80(4):555-561.

11. Desbois AP, Gemmell CG, Coote PJ. In vivo efficacy of the antimicrobial peptide ranalexin in combination with the endopeptidase lysostaphin against wound and systemic meticillin-resistant Staphylococcus aureus (MRSA) infections. Int J Antimicrob Agents. 2010;35(6):559-565.

12. Kokai-Kun JF, Walsh SM, Chanturiya T, Mond JJ. Lysostaphin cream eradicates Staphylococcus aureus nasal colonization in a cotton rat model. Antimicrob Agents Chemother. 2003;47(5):1589-1597.

13. Kusuma C, Jadanova A, Chanturiya T, Kokai-Kun JF. Lysostaphinresistant variants of Staphylococcus aureus demonstrate reduced fitness in vitro and in vivo. Antimicrob Agents Chemother. 2007;51(2): 475-482.

14. Cho JS, Zussman J, Donegan NP, et al. Noninvasive in vivo imaging to evaluate immune responses and antimicrobial therapy against Staphylococcus aureus and USA300 MRSA skin infections. J Invest Dermatol. 2011;131(4):907-915.

15. Cho JS, Pietras EM, Garcia NC, et al. IL-17 is essential for host defense against cutaneous Staphylococcus aureus infection in mice. J Clin Invest. 2010;120(5):1762-1773.

16. De Vry CG, Valdez M, Lazarov M, et al. Topical application of a novel immunomodulatory peptide, RDP58, reduces skin inflammation in the phorbol ester-induced dermatitis model. J Invest Dermatol. 2005;125(3):473-481.

17. Ward B, Seal BL, Brophy CM, Panitch A. Design of a bioactive cell-penetrating peptide: when a transduction domain does more than transduce. J Pept Sci. 2009;15(10):668-674.

18. Lopes LB, Brophy CM, Flynn CR, et al. A novel cell permeant peptide inhibitor of MAPKAP kinase II inhibits intimal hyperplasia in a human saphenous vein organ culture model. J Vasc Surg. 2010;52(6):1596-1607.

19. Schmelcher M, Powell AM, Becker SC, Camp MJ, Donovan DM. Chimeric phage lysins act synergistically with lysostaphin to kill mastitis-causing Staphylococcus aureus in murine mammary glands. Appl Environ Microbiol. 2012;78(7):2297-2305.

20. Rubin BK, Tamaoki J. Antibiotics as Anti-inflammatory and Immunomodulatory Agents. Basel: Birkhäuser; 2005.

21. Miller LS, Cho JS. Immunity against Staphylococcus aureus cutaneous infections. Nat Rev Immunol. 2011;11(8):505-518.

22. Cho JS, Guo Y, Ramos RI, et al. Neutrophil-derived IL-1 $\beta$ is sufficient for abscess formation in immunity against Staphylococcus aureus in mice. PloS Pathog. 2012;8(11):e1003047.

23. Jialal I, Miguelino E, Griffen SC, Devaraj S. Concomitant reduction of low-density lipoprotein-cholesterol and biomarkers of inflammation with low-dose simvastatin therapy in patients with type 1 diabetes. J Clin Endocrinol Metab. 2007;92(8):3136-3140. 
24. Wallace HJ, Stacey MC. Levels of tumor necrosis factor-alpha (TNF-alpha) and soluble TNF receptors in chronic venous leg ulcers - correlations to healing status. J Invest Dermatol. 1998;110(3): 292-296.

25. Cowin AJ, Hatzirodos N, Rigden J, Fitridge R, Belford DA. Etanercept decreases tumor necrosis factor-alpha activity in chronic wound fluid. Wound Repair Regen. 2006;14(4):421-426.
26. Donath MY. Targeting inflammation in the treatment of type 2 diabetes: time to start. Nat Rev Drug Discov. 2014;13(6):465-476.

27. Khanna S, Biswas S, Shang Y, et al. Macrophage dysfunction impairs resolution of inflammation in the wounds of diabetic mice. PloS One. 2010;5(3):e9539.

\section{Publish your work in this journal}

Drug Design, Development and Therapy is an international, peerreviewed open-access journal that spans the spectrum of drug design and development through to clinical applications. Clinical outcomes, patient safety, and programs for the development and effective, safe, and sustained use of medicines are a feature of the journal, which has also been accepted for indexing on PubMed Central. The manuscript management system is completely online and includes a very quick and fair peer-review system, which is all easy to use. Visit http://www.dovepress.com/testimonials.php to read real quotes from published authors.

Submit your manuscript here: http://www.dovepress.com/drug-design-development-and-therapy-journal 